\title{
Absolute Quantification in Proton Magnetic Resonance Spectroscopy Is Useful to Differentiate Amnesic Mild Cognitive Impairment from Alzheimer's Disease and Healthy Aging
}

\author{
Toshiyuki Watanabe $^{a, c}$ Akihiko Shiino $^{b, c}$ Ichiro Akiguchi ${ }^{a, d}$ \\ ${ }^{\text {a } D e p a r t m e n t ~ o f ~ N e u r o l o g y, ~ U j i-T a k e d a ~ H o s p i t a l, ~ U j i, ~}{ }^{\text {b } B i o m e d i c a l ~ M R ~ S c i e n c e ~ C e n t e r ~ a n d ~}{ }^{\mathrm{c} C e n t e r}$ of Neurological \\ Diseases, Shiga University of Medical Science, Otsu, and d Center of Neurological and Cerebrovascular Diseases, \\ Takeda Hospital, Kyoto, Japan
}

\section{Key Words}

Amnesic mild cognitive impairment · Alzheimer's

disease $\cdot$ Proton magnetic resonance spectroscopy •

$\mathrm{N}$-acetylaspartate $\cdot$ Choline compounds

\begin{abstract}
Background/Aims: Amnesic mild cognitive impairment (aMCl) is thought to represent a transitional state between healthy aging and very mild Alzheimer's disease (AD). It is very important to diagnose aMCl for early treatment. In order to investigate biochemical changes in $\mathrm{aMCl}$, we measured metabolite concentrations using proton magnetic resonance spectroscopy ('H-MRS) from patients with aMCl and compared the results with healthy controls $(\mathrm{HCs})$ and patients with AD. Methods: The subjects were $52 \mathrm{HCs}, 70 \mathrm{AD}$ patients and $47 \mathrm{aMCl}$ patients. ${ }^{1} \mathrm{H}-\mathrm{MR}$ spectra with singlevoxel point-resolved spectroscopy at a short echo time (TE) were acquired from 8 volumes of interest in the brain. $\boldsymbol{R e}$ sults: The bilateral hippocampal $\mathrm{N}$-acetylaspartate (NAA) concentrations from $\mathrm{aMCl}$ patients showed intermediate values, which were lower than those from $\mathrm{HC}$ subjects but higher than those from $A D$ patients. The patients with $\mathrm{aMCl}$ also had lower concentrations of NAA than HCs in the bilateral posterior periventricular and deep white matters (PDWM) and posterior cingulate gyrus and had lower levels
\end{abstract}

of choline compounds in the left posterior PDWM. Conclusion: Using a single-voxel ${ }^{1} \mathrm{H}-\mathrm{MRS}$ at a short TE, we revealed that absolute quantification is useful to detect the characteristic patterns of metabolite concentrations in patients with $\mathrm{aMCl}$ as compared with $\mathrm{AD}$ patients and $\mathrm{HCs}$.

Copyright $\odot 2010$ S. Karger AG, Basel

\section{Introduction}

Amnesic mild cognitive impairment (aMCI) is thought to represent a transitional state between healthy aging and very mild Alzheimer's disease (AD) [1]. Previous studies reported that several neuroimaging tools such as PET or SPECT are useful to discriminate aMCI from AD and healthy controls $[2,3]$. However, these tools are invasive and do not always have a high specificity for clinical diagnosis. Proton magnetic resonance spectroscopy $\left({ }^{1} \mathrm{H}-\right.$ MRS), a noninvasive tool, has also been used to measure the metabolite concentrations in patients with aMCI [422]. Among various substances assessed using ${ }^{1} \mathrm{H}-\mathrm{MRS}$, functional significances in 3 kinds of metabolites are interesting and have been discussed at length in the literature reporting on cognitive disorders: $\mathrm{N}$-acetylaspartate (NAA), myo-inositol (MI) and choline compounds (Cho) $[23,24]$. NAA is predominantly intraneuronal and has

\section{KARGER}

Fax +4161306 1234 E-Mail karger@karger.ch www.karger.com

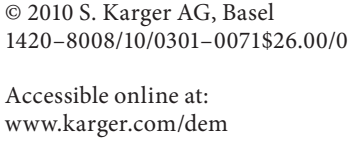


been widely used as a marker of neuronal density and viability. MI is primarily located in glial cells and has been interpreted to be a marker of gliosis. Cho may reflect the damaged cholinergic neurons in AD or aMCI. Although several previous studies reported a significant Cho elevation in $\mathrm{AD}$ patients, there is no consistent agreement on the change for this metabolite [23]. Most of the previous ${ }^{1} \mathrm{H}$-MRS studies have evaluated the relative ratio of NAA/ creatine (Cr), $\mathrm{MI} / \mathrm{Cr}$ or $\mathrm{Cho} / \mathrm{Cr}$ assuming that the concentration of $\mathrm{Cr}$ is stable. However, the $\mathrm{Cr}$ concentration has in fact been reported as variable with respect to the age of the patient, the site in the brain and the clinical stage of $\mathrm{AD}[25,26]$. It is therefore desirable to measure absolute concentrations of these metabolites. Several studies have measured the absolute concentrations of metabolites in the medial temporal lobe of aMCI, but the target voxels contained a large amount of brain tissue other than the hippocampus which is important for memory consolidation and believed to be damaged in early-stage $\mathrm{AD}[11,20,22]$, or arbitrary units were employed to express metabolite concentrations, which had made interinstitutional comparisons difficult [14]. In our previous studies $[25,26]$, we reported that absolute quantification in ${ }^{1} \mathrm{H}-\mathrm{MRS}$ from the hippocampus is superior to relative ratios to discriminate $\mathrm{AD}$ and vascular dementia from healthy aging. In this study, we would like to reveal the biochemical characteristics of aMCI by absolute quantification using ${ }^{1} \mathrm{H}$-MRS. By means of LC Model [27], which is fully automatic and lacks subjective interactions, we assessed the absolute metabolite concentrations from aMCI patients in the bilateral hippocampi and related regions, and then compared the results with those from AD patients and healthy controls (HCs). Aside from the bilateral hippocampi, we selected 6 volumes of interest (VOIs) for several reasons. Concerning the posterior cyngulate gyrus (PCG), recent functional studies including PET and SPECT suggest that a decrease in the metabolism or perfusion of the PCG is an early sign of AD $[2,3]$. Some ${ }^{1} \mathrm{H}-\mathrm{MRS}$ studies also investigated relative ratios of metabolites in the PCG. From a pathophysiological point of view, it is interesting to measure the metabolite concentrations from a patient with $\mathrm{AD}$ or $\mathrm{aMCI}$ in both hippocampi and PCG in vivo at one time. As for the periventricular and deep white matter (PDWM), we revealed in a previous paper that not only patients with subcortical ischemic vascular dementia (Binswanger's disease), but also patients with $\mathrm{AD}$ have reduced concentrations of NAA in the PDWM as compared with HCs [26]. In that same paper, we disclosed that the NAA concentrations of the patients with $\mathrm{AD}$ were reduced more prominently in the posterior PDWM than in the anterior PDWM as compared with healthy controls. Therefore, we are interested in examining the difference of NAA concentrations between the anterior and posterior PDWM in patients with aMCI. The occipital VOI was set as a reference position because the occipital lobe is thought to be relatively preserved in even advanced $\mathrm{AD}$ patients.

\section{Methods}

Subjects

All patients were recruited consecutively and prospectively for longitudinal studies of cognitive disturbances at our outpatient clinic. They underwent comprehensive diagnostic evaluations, including medical histories, neurological and psychiatric examinations, neuropsychological testing, laboratory tests as well as brain MRI and SPECT. The exclusion criteria were medical histories of cortical stroke or other major neurological diseases, thyroid dysfunctions, seizures, alcohol abuse and psychiatric disorders. Dementia was diagnosed in accordance with the Diagnostic and Statistical Manual of Mental Disorders, fourth edition [28]. Patients with AD fulfilled the NINCDS-ADRDA criteria for probable AD [29]. Dementia severity in AD was assessed with the Clinical Dementia Rating Scale [30], and only patients with mild to moderate severity (scores 1 or 2 ) were studied. Patients with aMCI had to meet the operational criteria proposed by Grundman et al. [1] including: (1) memory complaint, corroborated by informants; (2) abnormal memory function, documented by delayed recall of 1 paragraph from the Logical Memory II subtest of the Revised Wechsler Memory Scale; (3) normal general cognitive function, as determined by a clinician's judgment based on a structured interview with the patient and informant (Clinical Dementia Rating) and the Mini Mental State Examination (MMSE) score $[31] \geq 24$; (4) no or minimal impairment in activities of daily living, as determined by a clinical interview with the patient and informants, and (5) not sufficiently impaired, cognitively and functionally, to meet NINCDS-ADRDA criteria for AD. Cognitive function was examined with the MMSE, the Alzheimer's Disease Assessment Scale cognitive subscale, Revised Wechsler Adult Intelligence Scale [32] and Revised Wechsler Memory Scale [33].

Eighty-seven patients with $\mathrm{AD}$ and 64 patients with aMCI were recruited during May 2001 and August 2009. On the basis of the above-mentioned criteria, however, we studied 70 patients with $\mathrm{AD}, 47$ patients with aMCI and 52 age-matched $\mathrm{HC}$ subjects. The HC subjects were volunteers for the study project of MCI in our facilities. None of the control subjects had any severe neurological or medical diseases. The protocol was approved by the local ethics committee, and informed consent was obtained from all participants and their responsible caregivers in accordance with the Declaration of Helsinki.

$M R I$ and ${ }^{1} H-M R S$

${ }^{1} \mathrm{H}$-MRS was performed on all patients suspected of AD or aMCI excluding those for whom MRI is contraindicated, such as patients with an artificial pacemaker or claustrophobia. The study protocol has been previously described in detail [26]. Briefly, both MRI and ${ }^{1} \mathrm{H}$-MRS were performed on a 1.5-tesla appara- 

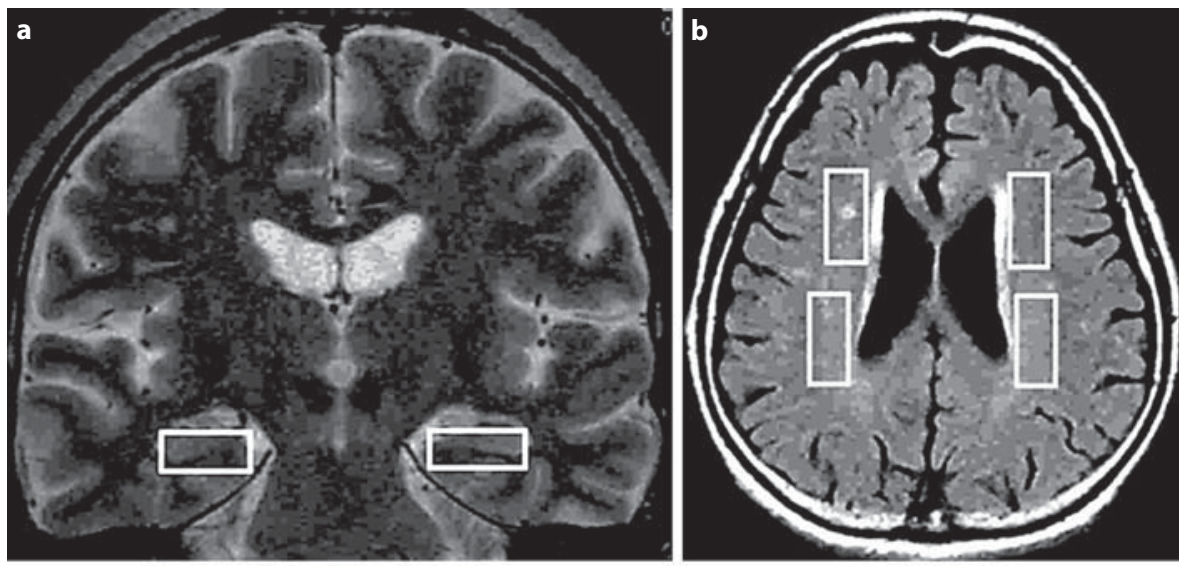

Fig. 1. Locations of VOIs for ${ }^{1} \mathrm{H}-\mathrm{MRS}$ : bilateral hippocampi (a); bilateral anterior and posterior PDWM (b); PCG (c); occipital lobe (d). In the PCG and the occipital lobe, VOIs were located in paramedian positions.
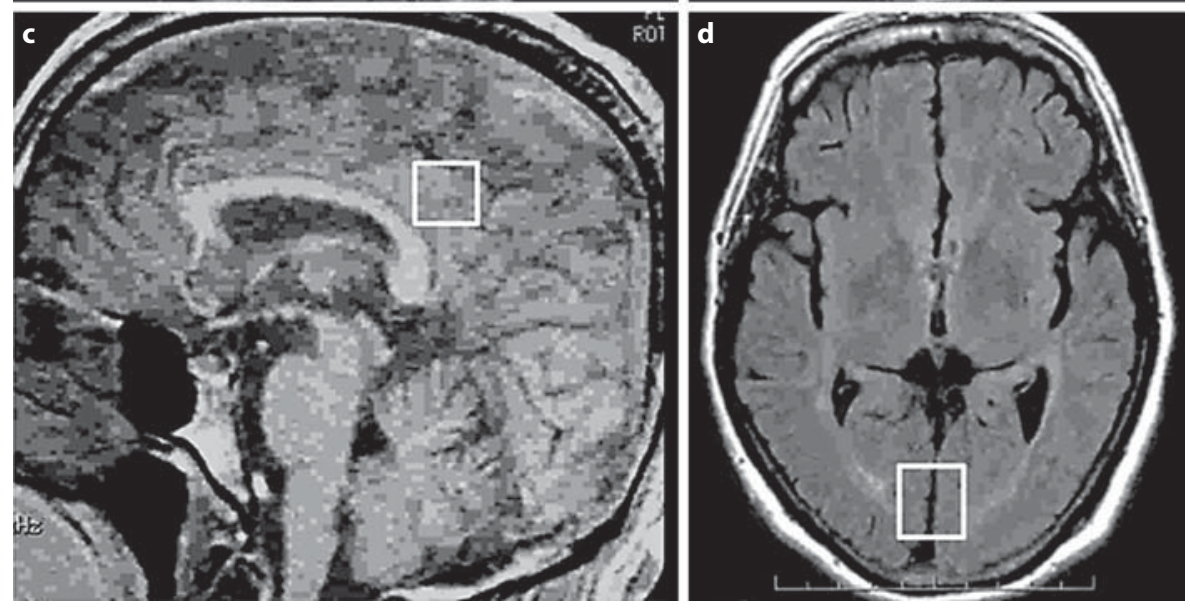

tus (Signa LX; General Electric Medical System, Milwaukee, Wisc., USA) using a standard head coil suited for MRI and MRS. The protocol for structural MRI included axial fluid-attenuated inversion recovery images with repetition time/echo time (TE)/ inversion time $=4,000 / 124 / 2,000 \mathrm{~ms}$ with a slice thickness of $4 \mathrm{~mm}$. As shown in figure 1 , the VOIs for ${ }^{1} \mathrm{H}$-MRS were assigned to 8 areas in the brain: bilateral anterior PDWM, bilateral posterior PDWM, bilateral hippocampi, PCG and occipital lobe. To establish the VOIs for the hippocampi, sagittal images were obtained, followed by tilted $\mathrm{T}_{2}$-weighted (repetition time/TE $4,000 / 107 \mathrm{~ms}$ ) coronal images perpendicular to the long axis of the hippocampus with a slice thickness of $3 \mathrm{~mm}$. A rectangular VOI was placed along the long axis of the hippocampus and contained the hippocampal head and body about $15 \mathrm{~mm}$ from just posterior to the amygdala. With repetition time/TE $2,000 / 30 \mathrm{~ms}$ and 192 signal averages, ${ }^{1} \mathrm{H}$-MRS spectra were acquired with point-resolved spectroscopy volume selection. Spectral analyses were performed using a spectroscopy software package for the Sun Workstation. Absolute concentrations were calculated using LC Model [27]. Corrections for gray and white matter with respect to $\mathrm{T}_{1}$ - and $\mathrm{T}_{2}$-weighted relaxation times were performed according to data by Kreis et al. [34] and for hippocampi by Choi and Frahm [35]. As to the hippocampus, the voxel contained variable amounts of CSF due to tissue atrophy. We compensated for CSF by calculating $\mathrm{T}_{2}$ components of water in each coronal slice [26].
Statistical Analyses

All comparisons of the means from the demographic data were tested by an analysis of variance (ANOVA) followed by Scheffé's post hoc test. As for metabolite concentrations obtained with ${ }^{1} \mathrm{H}$-MRS, group differences were analyzed by 3 -factorial multivariate ANOVA using voxels $(\times 8)$ and metabolites $(\times 4)$ as within factors and as between factors for the 3 groups, followed by post hoc univariate ANOVA with Scheffé's test to determine differences between groups. The statistical analyses were performed with SPSS version 13.0 (SPSS Inc., Chicago, Ill., USA). A $p$ value $<0.05$ was considered to be statistically significant.

\section{Results}

The demographic and clinical characteristics of the subjects are summarized in table 1 . We found no group difference on age or education using one-way ANOVA. It showed significant differences in the mean score of MMSE among the 3 groups $(\mathrm{p}<0.001)$, and the post hoc Scheffé's test disclosed significant differences between $\mathrm{HC}$ and $\mathrm{AD}$ groups $(\mathrm{p}<0.001)$, between $\mathrm{HC}$ and $\mathrm{aMCI}$ 
Fig. 2. Absolute concentrations (mmol/l) in metabolites. In each 3 box plots, the left is for $\mathrm{HC}$, the middle for $\mathrm{AD}$ and the right for aMCI subjects. $\mathrm{RH}=$ Right hippocampus; $\mathrm{LH}=$ left hippocampus; $\mathrm{PC}=\mathrm{PCG}$; $\mathrm{OL}=$ occipital lobe; $\mathrm{RA}=$ right anterior PDWM; LA = left anterior PDWM; RP = right posterior PDWM; LP = left posterior PDWM. ${ }^{\mathrm{a}} \mathrm{p}<0.01 ;{ }^{\mathrm{b}} \mathrm{p}<0.05$, relative to $\mathrm{HC} ;{ }^{\mathrm{c}} \mathrm{p}<0.01$, relative to AD.

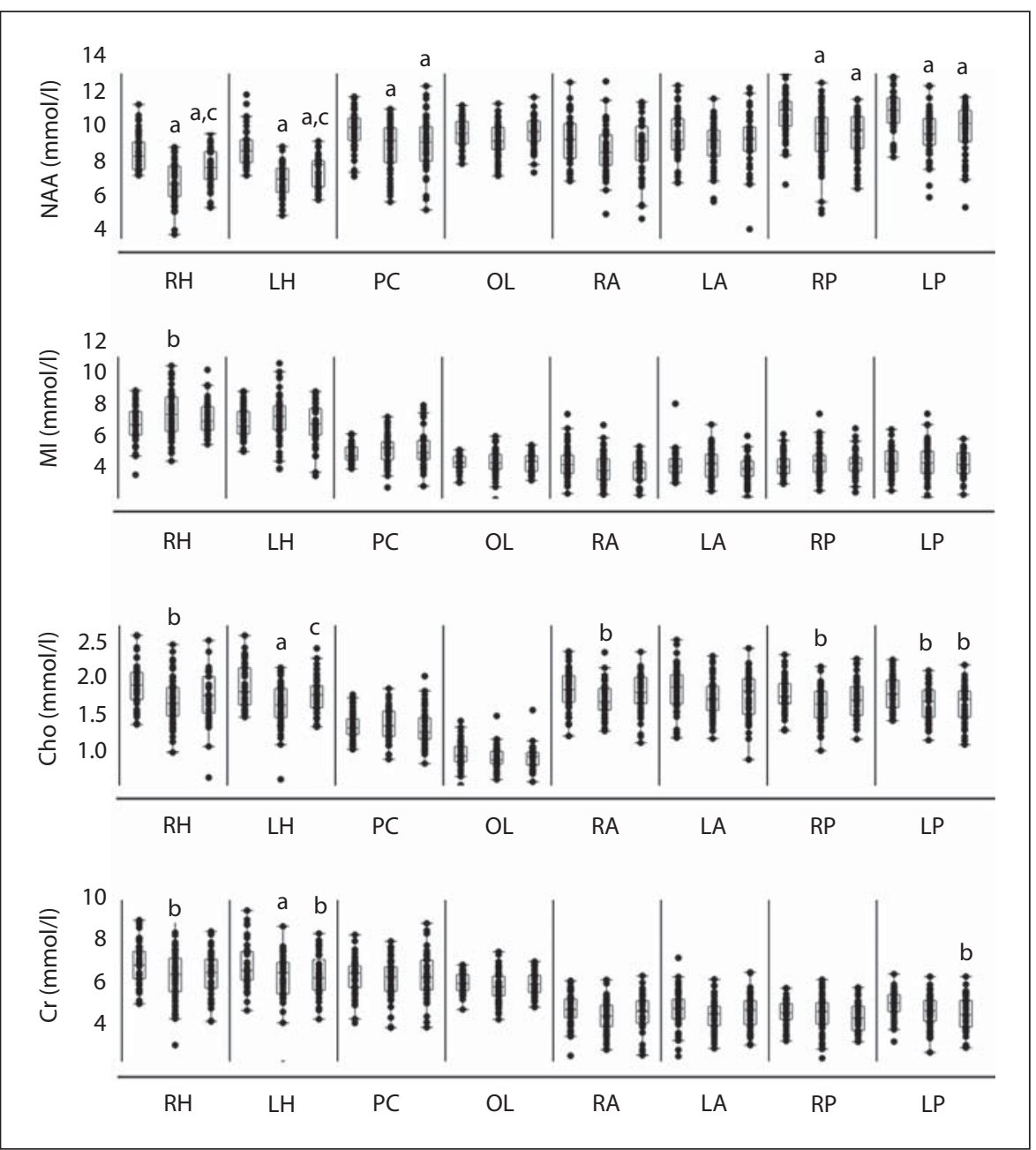

Table 1. Clinical characteristics of patients with $\mathrm{AD}$, aMCI and of HC subjects

\begin{tabular}{lccc}
\hline & HC & AD & aMCI \\
\hline Number of subjects & 52 & 70 & 47 \\
Women/men & $33 / 19$ & $51 / 19$ & $23 / 24$ \\
Age, years & $69.4 \pm 6.1$ & $72.1 \pm 7.6$ & $71.2 \pm 7.3$ \\
Age range & $60-81$ & $55-83$ & $54-84$ \\
Education, years & $10.8 \pm 0.6$ & $11.4 \pm 0.4$ & $11.9 \pm 0.5$ \\
MMSE score & $29.0 \pm 1.4$ & $20.8 \pm 3.6^{\mathrm{a}}$ & $27.2 \pm 1.8^{\mathrm{a}, \mathrm{b}}$ \\
\hline
\end{tabular}

Data for age, education and MMSE score are given as the mean $\pm \mathrm{SD} .{ }^{\mathrm{a}} \mathrm{p}<0.01$ (Scheffé's test) relative to HC; ${ }^{\mathrm{b}} \mathrm{p}<0.01$ (Scheffé's test) relative to $\mathrm{AD}$. groups $(\mathrm{p}<0.001)$, and between $\mathrm{AD}$ and aMCI groups $(p<0.001)$. The report concerning the results of other neuropsychological examinations will be prepared for the next paper.

Using ${ }^{1} \mathrm{H}-\mathrm{MRS}$, the absolute concentrations of $\mathrm{N}$-acetyl compounds, MI, Cr and Cho were obtained. The $\mathrm{N}$-acetyl compounds contained not only $\mathrm{N}$-acetylaspartate, but also $\mathrm{N}$-acetylaspartylglutamate, and were expressed as NAA.

The absolute metabolite concentrations are presented as means $\pm \mathrm{SD}(\mathrm{mmol} / \mathrm{l})$ in table 2 and figure 2 . We checked the metabolite concentrations of NAA, MI, Cho and $\mathrm{Cr}$ for normality of distribution. Concerning gender, there were no differences between men and women in each metabolite concentration in any VOI. Overall, multivariate ANOVA revealed a significant group difference among the 3 groups $(\mathrm{p}<0.01)$. Concerning NAA concentrations, post hoc univariate ANOVA was performed in- 
Table 2. Absolute concentrations of metabolites (mmol/l) from patients with AD, aMCI and of HCs

\begin{tabular}{|c|c|c|c|c|c|c|c|c|c|}
\hline Metabolites & Group & RH & LH & PC & OL & RA & LA & $\mathrm{RP}$ & LP \\
\hline \multirow[t]{3}{*}{ NAA } & $\mathrm{HC}$ & $8.45 \pm 1.00$ & $8.71 \pm 1.00$ & $9.78 \pm 1.02$ & $9.59 \pm 0.81$ & $9.25 \pm 1.33$ & $9.48 \pm 1.36$ & $10.60 \pm 1.18$ & $10.80 \pm 1.17$ \\
\hline & $\mathrm{AD}$ & $6.80 \pm 1.12^{\mathrm{a}}$ & $6.82 \pm 1.12^{\mathrm{a}}$ & $8.87 \pm 1.35^{\mathrm{a}}$ & $9.16 \pm 0.93$ & $8.61 \pm 1.34$ & $8.97 \pm 1.16$ & $9.43 \pm 1.56^{\mathrm{a}}$ & $9.57 \pm 1.21^{\mathrm{a}}$ \\
\hline & $\mathrm{aMCI}$ & $7.61 \pm 1.05^{\mathrm{a}, \mathrm{c}}$ & $7.45 \pm 0.85^{\mathrm{a}, \mathrm{c}}$ & $8.97 \pm 1.47^{\mathrm{a}}$ & $9.62 \pm 0.82$ & $8.82 \pm 1.53$ & $9.14 \pm 1.46$ & $9.49 \pm 1.27^{\mathrm{a}}$ & $9.70 \pm 1.40^{\mathrm{a}}$ \\
\hline \multirow[t]{3}{*}{ MI } & $\mathrm{HC}$ & $7.21 \pm 1.32$ & $7.33 \pm 1.12$ & $5.03 \pm 0.65$ & $4.33 \pm 0.54$ & $4.31 \pm 1.10$ & $4.17 \pm 1.06$ & $4.18 \pm 0.83$ & $4.37 \pm 0.98$ \\
\hline & $\mathrm{AD}$ & $8.01 \pm 1.82^{\mathrm{b}}$ & $7.70 \pm 1.60$ & $5.37 \pm 1.04$ & $4.39 \pm 0.89$ & $3.94 \pm 1.09$ & $4.23 \pm 1.11$ & $4.42 \pm 1.10$ & $4.45 \pm 1.28$ \\
\hline & $\mathrm{aMCI}$ & $7.62 \pm 1.19$ & $7.24 \pm 1.45$ & $5.34 \pm 1.30$ & $4.33 \pm 0.71$ & $3.75 \pm 0.92$ & $3.89 \pm 0.94$ & $4.24 \pm 0.97$ & $4.30 \pm 0.94$ \\
\hline \multirow[t]{3}{*}{ Cho } & $\mathrm{HC}$ & $1.89 \pm 0.29$ & $1.87 \pm 0.30$ & $1.33 \pm 0.18$ & $0.93 \pm 0.18$ & $1.84 \pm 0.27$ & $1.84 \pm 0.30$ & $1.76 \pm 0.22$ & $1.78 \pm 0.22$ \\
\hline & $\mathrm{AD}$ & $1.71 \pm 0.40^{\mathrm{b}}$ & $1.61 \pm 0.29^{\mathrm{a}}$ & $1.34 \pm 0.22$ & $0.88 \pm 0.14$ & $1.69 \pm 0.22^{\mathrm{b}}$ & $1.72 \pm 0.25$ & $1.61 \pm 0.25^{\mathrm{b}}$ & $1.64 \pm 0.27^{\mathrm{b}}$ \\
\hline & $\mathrm{aMCI}$ & $1.74 \pm 0.35$ & $1.76 \pm 0.26^{c}$ & $1.30 \pm 0.25$ & $0.89 \pm 0.11$ & $1.78 \pm 0.27$ & $1.75 \pm 0.32$ & $1.70 \pm 0.27$ & $1.62 \pm 0.26^{\mathrm{b}}$ \\
\hline \multirow[t]{3}{*}{$\mathrm{Cr}$} & $\mathrm{HC}$ & $7.06 \pm 0.96$ & $7.11 \pm 1.13$ & $6.51 \pm 0.81$ & $6.23 \pm 0.46$ & $4.99 \pm 0.73$ & $5.01 \pm 0.88$ & $4.87 \pm 0.61$ & $5.23 \pm 0.61$ \\
\hline & $\mathrm{AD}$ & $6.55 \pm 1.16^{\mathrm{b}}$ & $6.51 \pm 1.03^{\mathrm{a}}$ & $6.43 \pm 0.86$ & $6.03 \pm 0.67$ & $4.65 \pm 0.74$ & $4.73 \pm 0.68$ & $4.79 \pm 0.78$ & $4.93 \pm 0.71$ \\
\hline & $\mathrm{aMCI}$ & $6.64 \pm 1.02$ & $6.58 \pm 0.95^{\mathrm{b}}$ & $6.51 \pm 1.01$ & $6.19 \pm 0.56$ & $4.86 \pm 0.81$ & $4.90 \pm 0.78$ & $4.62 \pm 0.65$ & $4.79 \pm 0.65^{b}$ \\
\hline
\end{tabular}

Data are given as the mean $\pm \mathrm{SD}$. $\mathrm{RH}=$ Right hippocampus; $\mathrm{LH}=$ left hippocampus; $\mathrm{PC}=\mathrm{PCG}$; OL = occipital lobe; $\mathrm{RA}=$ right anterior PDWM; $\mathrm{LA}=$ left anterior PDWM; RP = right posterior PDWM; LP = left posterior PDWM. ${ }^{\mathrm{a}} \mathrm{p}<0.01,{ }^{\mathrm{b}} \mathrm{p}<0.05$, relative to $\mathrm{HC}$; ${ }^{\mathrm{c}} \mathrm{p}<0.01$, relative to AD.

dividually on each region and showed a group difference in the PCG, bilateral hippocampi and posterior PDWM. With regard to the bilateral hippocampi, Scheffé's test revealed that aMCI patients had intermediate values, which were lower than those of HC subjects $(\mathrm{p}<0.01)$ but higher than those of $A D$ patients $(\mathrm{p}<0.01)$. Patients with aMCI and AD had lower levels of NAA than HC subjects in the PCG and bilateral posterior PDWM. The NAA levels of these 3 VOIs were not significantly different between $\mathrm{aMCI}$ and $\mathrm{AD}$ groups.

As to MI concentrations, post hoc analyses showed no difference between aMCI and HC groups in any VOI. In the right hippocampus, patients with $\mathrm{AD}$ had significantly higher levels of MI than HC subjects ( $p=0.046)$.

With regard to Cho concentrations, Scheffé's test disclosed that aMCI patients had significantly lower levels than HC subjects in the left posterior PDWM and higher levels than AD patients in the left hippocampus. Decreases in Cho levels in the bilateral hippocampi, bilateral anterior PDWM and the right posterior PDWM were also measured in patients with aMCI relative to controls, but the decrease did not reach statistical significance. Cho concentrations of $\mathrm{AD}$ patients were significantly lower than those of HC subjects in the bilateral hippocampi, right anterior PDWM and bilateral posterior PDWM.

Concerning Cr concentrations, Scheffé's test revealed that Cr levels of the aMCI group in the left hippocampus and left posterior PDWM were significantly lower than those of HC subjects. AD patients had significantly lower levels of $\mathrm{Cr}$ than $\mathrm{HC}$ subjects in the bilateral hippocampi.

\section{Discussion}

In this study, we revealed that aMCI patients have intermediate levels of NAA concentrations in the bilateral hippocampi, which are lower than those of $\mathrm{HC}$ subjects but higher than those of $\mathrm{AD}$ patients. This biochemical finding is compatible with the fact that aMCI patients have MMSE scores that are in-between those of HC subjects and AD patients (table 1). Patients with aMCI have lower concentrations of NAA than HC subjects in the PCG and bilateral posterior PDWM which are not significantly different from those of AD patients. NAA is an amino acid found primarily in neurons of the adult brain and has been proposed as a marker of neuronal function and density involved in facilitating energy metabolism in neuronal mitochondria [24]. Our present findings suggest that degenerative biochemical changes in the PCG and posterior PDWM may precede those in the hippocampi, but that the latter may reflect the cognitive changes observed in aMCI patients because test scores of the MMSE and Revised Wechsler Memory Scale have stronger correlations with the concentrations of the hippocampi than those of the PCG [manuscript in preparation].

As to MI concentrations, there is no difference between aMCI and HC groups in any VOI. Patients with AD have significantly higher levels of MI than HC subjects only in the right hippocampus. MI is mainly located in glial cells and has been interpreted to be a marker of gliosis [23]. Several studies reported elevated MI/Cr in 
the PCG of AD [7, 12] and MCI [7], but others have not confirmed the increase in $\mathrm{MI} / \mathrm{Cr}$ in the paratrigonal white matter of aMCI [17] or in the left temporal lobe of $\mathrm{AD}$ or MCI [20]. Our present data suggest that there is a tendency of elevation of MI concentration in the brain of aMCI but that the tendency is lower than that of NAA concentration.

Concerning Cho concentrations in $\mathrm{AD}$ or aMCI, previous studies are perplexing. The Cho peak in ${ }^{1} \mathrm{H}$-MRS measures total levels of mobile Cho, which include free choline, acetylcholine (present in relatively minute quantities), glycerophosphorylcholine (a byproduct of phosphatidylcholine breakdown) and phosphocholine (a phosphatidylcholine precursor) [23]. Membrane phosphatidylcholine is invisible on ${ }^{1} \mathrm{H}-\mathrm{MRS}$. Kantarci et al. [8] reported that $\mathrm{Cho} / \mathrm{Cr}$ of patients with aMCI or $\mathrm{AD}$ was higher than that of HCs in the PCG and described that one possible explanation for elevation of Cho in ${ }^{1} \mathrm{H}-\mathrm{MRS}$ studies of these patients was increased membrane turnover due to neuronal degeneration. In contrast, Jessen et al. [36] showed that $\mathrm{Cho/Cr}$ in the medial temporal lobe was decreased in patients with $\mathrm{AD}$ as compared with control subjects. In addition, Jessen et al. [37] described that Cho/Cr correlated with the decline of the MMSE and that their finding would represent a reduction of Cho with cognitive deterioration seen in $\mathrm{AD}$ patients. Chantal et al. [11] reported decreased $\mathrm{Cho} / \mathrm{H}_{2} \mathrm{O}$ in the medial temporal lobe of $\mathrm{AD}$ patients but no difference between aMCI patients and HCs. Franczak et al. [38] showed that patients with aMCI had lower levels of Cho concentrations than controls in the bilateral hippocampi.

Our present study revealed that absolute Cho concentrations of $\mathrm{AD}$ patients were reduced in the bilateral hippocampi, right anterior PDWM and bilateral posterior PDWM. Patients with aMCI also showed reduced Cho levels in the left posterior PDWM. There was a trend to- ward decreased Cho concentrations in the bilateral hippocampi, bilateral anterior PDWM and the right posterior PDWM of patients with aMCI relative to controls. Our findings showed that Cho concentrations in the brains of patients with aMCI and AD are reduced and suggest that membrane turnover decreases in these patients in contrast to the influential proposal by Kantarci et al. [8].

Wang et al. [39] showed that Cho signal intensity measured by ${ }^{1} \mathrm{H}-\mathrm{MRS}$ and the acetylcholine level assessed by microdialysis and high-performance liquid chromatography in the hippocampus was positively correlated in rats and suggested that Cho signal intensity observed by ${ }^{1} \mathrm{H}-\mathrm{MRS}$ may be used as an indicator of acetylcholine level in the rat hippocampus. The decreased Cho level disclosed by our study may reflect the reduced acetylcholine in the hippocampus of aMCI and AD patients.

Cr concentrations were reduced in the left hippocampus and left posterior PDWM of aMCI patients and in the bilateral hippocampi of $\mathrm{AD}$ patients. As we have reported in the previous paper [26], the fluctuations of the Cr level of aMCI and AD have been confirmed in the present study, especially in the hippocampus. Absolute quantification of brain metabolites is superior to the relative ratio using $\mathrm{Cr}$ as a reference.

Using a single-voxel ${ }^{1} \mathrm{H}$-MRS at a short TE, we revealed that absolute quantification is useful to detect the characteristic patterns of metabolite concentrations in patients with aMCI and $\mathrm{AD}$.

\section{Acknowledgments}

We thank Dr. Emi Kotani for neuropsychological examinations on the subjects and Drs. Don Block and Hazel Gonzalez for their native check on the English manuscript.

\section{References}

1 Grundman M, Petersen RC, Ferris SH, Thomas RG, Alsen PS, Bennet DA, et al: Mild cognitive impairment can be distinguished from Alzheimer disease and normal aging for clinical trials. Arch Neurol 2004;61:5966.

2 Chetelat G, Desgranges B, de la Sayette V, Viader F, Eustache F, Baron JC: Mild cognitive impairment: can FDG-PET predict who is to rapidly convert to Alzheimer's disease? Neurology 2003;60:1374-1377.
3 Drzezga A, Lautenschlager N, Siebner $\mathrm{H}$, Riemenschneider M, Willoch F, Minoshima $S$, et al: Cerebral metabolic changes accompanying conversion of mild cognitive impairment into Alzheimer's disease: a PET follow-up study. Eur J Nucl Med Mol Imaging 2003;30:1104-1113.

4 Kantarci K, Jack CR, Xu YC, Campeau NG, O’Brien PC, Smith GE, et al: Regional metabolic patterns in mild cognitive impairment and Alzheimer's disease: a ${ }^{1} \mathrm{H}$ MRS study. Neurology 2000;25:210-217.
Kantarci K, Xu YC, Shiung MM, O’Brien PC, Cha RH, Smith GE, et al: Comparative diagnostic utility of different MR modalities in mild cognitive impairment and Alzheimer's disease. Dementia Geriatr Cogn Disord 2002;14:198-207.

-6 Kantarci K, Reynolds G, Xu YC, Petersen RC, Boeve BF, Knopman D, et al: Proton MR spectroscopy in mild cognitive impairment and Alzheimer disease: comparison of 1.5 and 3T. AJNR Am J Neuroradiol 2003;24: 843-849. 
7 Kantarci K, Petersen RC, Boeve BF, Knopman DS, Tang-Wai DF, O'Brien PC, et al: ${ }^{1} \mathrm{H}$ MR spectroscopy in common dementias. Neurology 2004;63:1393-1398.

8 Kantarci K, Weigand SD, Petersen RC, Boeve BF, Knopman DS, Gunter J, et al: Longitudinal ${ }^{1} \mathrm{H}$ MRS changes in mild cognitive impairment and Alzheimer's disease. Neurobiol Aging 2006;28:1330-1339.

9 Kantarci K, Weigand SD, Przybelski SA, Shiung MM, Whitwell JL, Negash S, et al: Risk of dementia in MCI: combined effect of cerebrovascular disease, volumetric MRI, and ${ }^{1} \mathrm{H}$ MRS. Neurology 2009;72:1519-1525.

-10 Catani M, Cherubini A, Howard R, Tarducci R, Pelliccioli GP, Piccirilli M, et al: ${ }^{1} \mathrm{H}-\mathrm{MR}$ spectroscopy differentiates mild cognitive impairment from normal brain aging. Neuroreport 2003;12:2315-2317.

- 11 Chantal S, Braun CM, Bouchard RW, Labelle $\mathrm{M}$, Boulanger Y: Similar ${ }^{1} \mathrm{H}$ magnetic resonance spectroscopic metabolic pattern in the medial temporal lobes of patients with mild cognitive impairment and Alzheimer disease. Brain Res 2004;1003:26-35.

-12 Martinez-Bisbal MC, Arana E, Marti-Bonmati L, Molla E, Celda B: Cognitive impairment: classification by ${ }^{1} \mathrm{H}$ magnetic resonance spectroscopy. Eur J Neurol 2004;11: 187-193.

-13 Ackl N, Ising M, Schreiber YA, Atiya M, Sonntag A, Auer D: Hippocampal metabolic abnormalities in mild cognitive impairment and Alzheimer's disease. Neurosci Lett 2005; 384:23-28.

- 14 Chao LL, Schuff N, Kramer JH, Du AT, Capizzano AA, O’Neill J, et al: Reduced medial temporal lobe $\mathrm{N}$-acetylaspartate in cognitively impaired nondemented patients. Neurology 2005;64:282-289.

- 15 Falini A, Bozzali M, Magnani G, Pero G, Gambini A, Benedetti B, et al: A whole brain MR spectroscopy study from patients with Alzheimer's disease and mild cognitive impairment. Neuroimage 2005;26:1159-1163.

-16 Modrego PJ, Fayed N, Pina MA: Conversion from mild cognitive impairment to probable Alzheimer's disease predicted by brain magnetic resonance spectroscopy. Am J Psychiatry $2005 ; 162: 667-675$.
17 Metastasio A, Rinaldi P, Tarducci R, Mariani E, Feliziani FT, Cherubini A, et al: Conversion of MCI to dementia: role of proton magnetic resonance spectroscopy. Neurobiol Aging 2006;27:926-932.

18 Perneczky R, Hartmann J, Grimmer T, Drzezga A, Kurz A: Cerebral metabolic correlates of the clinical dementia rating scale in mild cognitive impairment. J Geriatr Psychiatry Neurol 2007;20:84-88.

19 Garcia Santos JM, Gavrilla D, Antunez C Tormo MJ, Salmeron D, Carles R, et al: Magnetic resonance spectroscopy performance for detection of dementia, Alzheimer's disease and mild cognitive impairment in a community-based survey. Dementia Geriatr Cogn Disord 2008;26:15-25.

20 Jessen F, Gur O, Block W, Ende G, Frolich L, Hammen T, et al: A multicenter ${ }^{1} \mathrm{H}-\mathrm{MRS}$ study of the medial temporal lobe in AD and MCI. Neurology 2009;72:1735-1740.

21 Zhang B, Li M, Sun ZZ, Zhu B, Yuan L, Wang $Y$, et al: Evaluation of functional MRI markers in mild cognitive impairment. J Clin Neurosci 2009;16:635-641.

22 Rupsingh R, Borrie M, Smith M, Wells JL, Bartha R: Reduced hippocampal glutamate in Alzheimer disease. Neurobiol Aging 2009, E-pub ahead of print.

23 Valenzuela MJ, Sachdev P: Magnetic resonance spectroscopy in Alzheimer's disease. Neurology 2001;56:592-598.

24 Moffett JR, Ross B, Arun P, Madhavarao CN, Namboodiri AMA: $\mathrm{N}$-acetylaspartate in the CNS: from neurodiagnostics to neurobiology. Prog Neurobiol 2007;81:89-131.

25 Watanabe T, Akiguchi I, Yagi H, Onishi K, Kawasaki T, Shiino A, et al: Proton magnetic resonance spectroscopy and white matter hyperintensities on magnetic resonance imaging in patients with Alzheimer's disease. Ann NY Acad Sci 2002;977:423-429.

26 Watanabe T, Shiino A, Akiguchi I: Absolute quantification in proton magnetic resonance spectroscopy is superior to relative ratio to discriminate Alzheimer's disease from Binswanger's disease. Dement Geriatr Cogn Disord 2008;26:89-100.

-27 Provencher SW: Estimation of metabolite concentrations from localized in vivo proton NMR spectra. Magn Reson Med 1993;30: 672-679.

28 American Psychiatric Association: Diagnostic and Statistical Manual of Mental Disorders, ed 4. Washington, American Psychiatric Association, 1994
29 McKhann G, Drachman D, Folstein M, Katzman R, Price D, Stadlan EM: Clinical diagnosis of Alzheimer's disease: report of the NINCDS-ADRDA Work Group under the auspices of Department of Health and $\mathrm{Hu}-$ man Services Task Force on Alzheimer's disease. Neurology 1984;34:939-944.

30 Morris JC: The Clinical Dementia Rating (CDR): current version and scoring rules. Neurology 1993;43:2412-2414.

31 Folstein MF: Mini Mental State: a practical method for grading the cognitive state of patients for the clinician. J Psychiatr Res 1975; 12:189-198.

32 Shinagawa F, Kobayashi S, Fujita K, Maekawa H: Japanese Wechsler Adult Intelligence Scale Revised (in Japanese). Tokyo, Nihon Bunka Kagakusha, 1990

33 Sugishita M: Japanese Wechsler Memory Scale Revised (in Japanese). Tokyo, Nihon Bunka Kagakusha, 2001.

34 Kreis R, Ernst T, Ross BD: Absolute quantification of water and metabolites in the human brain. 2. Metabolite concentrations. J Magn Reson Ser B 1993;102:9-19.

35 Choi CG, Frahm J: Localized proton MRS of the human hippocampus: metabolite concentrations and relaxation times. Magn Reson Med 1999;41:204-207.

$>36$ Jessen F, Block W, Traber F, Keller E, Flacke S, Papassotiropoulos A, et al: Proton MR spectroscopy detects a relative decrease of $\mathrm{N}$ acetylaspartate in the medial temporal lobe of patients with AD. Neurology 2000;55: 684-688.

-37 Jessen F, Block W, Traber F, Keller E, Flacke $\mathrm{S}$, Lamerichs R, et al: Decrease of $\mathrm{N}$-acetylaspartate in the MTL correlates with cognitive decline of AD. Neurology 2001;57:930-932.

-38 Franczak M, Prost RW, Antuouno PG, Mark LP, Jones JL, Ulmer JL: Proton magnetic resonance spectroscopy of the hippocampus in patients with mild cognitive impairment: a pilot study. J Comp Assist Tomogr 2007;31: 666-670.

-39 Wang XC, Du XX, Tian Q, Wang JZ: Correlation between choline signal intensity and acetylcholine level in different brain regions of rat. Neurochem Res 2008;33:814-819. 